\title{
An Interactive and Experiential Game for Promoting Organizational Values
}

\author{
Heini Ikävalko and Miia Martinsuo \\ Helsinki University of Technology, Department of Industrial Engineering and Management
}

E-mail: heini.ikavalko@hut.fi, miia.martinsuo@hut.fi

Key words: Simulation games, organizational values, value statements,

\begin{abstract}
This paper presents the design process and features of a tailored, interactive and experiential simulation game that is used to promote the values of an electronics industry firm. The game design is evaluated to discover essential features in the games used for promoting values.
\end{abstract}

\section{INTRODUCTION}

In promoting organizational values, priorities and ways of working are the focus, one of the means for which in the promotion process is the simulation game. Current simulation games fail to reveal how they could be used to promote organizationally relevant values in particular, and present the adoption or discussion of values as a sideline to other topics.

\subsection{Experience from simulation games}

Simulation games have different kinds of applications in organization management ranging from teaching and training to research purposes. Practising strategic management (Keys 1997), developing work processes (Piispanen et al 1996), and simulating managerial decision making (Beazley 
\& Lobuts 1996) can be mentioned as examples of using games in management-related issues.

Simulation games can succeed in increasing motivation, conveying information or increasing awareness of policies and issues, developing decision making, communication or other kinds of skills, changing attitudes, and in self-evaluation for instance in terms of the awareness of one's own assumptions and attitudes (Greenblat 1988). Experience gained in simulation games, especially when used for improving work processes, suggests that games promote the learning of new priorities and ways of working (Piispanen et al. 1996, Ruohomäki 1994, 1995, Piispanen 1995, ForssénNyberg \& Kutilainen 1998, Haho 1998, Smeds 1996). Some games have even been said to transmit values or handle value conflicts (see Goldstein 1996, Beazley \& Lobuts 1996). To date, there have been no reports on using games to communicate and promote organizational values in particular.

One of the major benefits of simulation games is the active involvement of participants. This active involvement makes the learning process in simulation games different from more traditional ways of learning, such as lectures. The experience of the topic as a whole, understanding system characteristics as well as using game-specific symbols can be considered as other advantages of simulation games (see Greenblat 1988). The problems of simulation games can often be related to their generality and, thus, poor transfer of learning to a real life context. Only now is the trend more towards case and industry realism, visual images, and learning transfer in strategic management games (Keys 1997).

\subsection{Motives to promote organizational values}

Values have received an elevated position in organizational management during the past 25 years. From an individual point of view, values are abstract ideals, positive or negative, not tied to any specific attitude, object or situation, representing a person's beliefs about ideal modes of conduct and ideal terminal goals (Rokeach 1968). Values are both consciously and unconsciously, and individually and collectively held (Kluckhohn and Strodtbeck 1961). People adopt certain values early in their childhood from the surrounding society, and these values are difficult if not impossible to change. However, organizational managers can use their values, often written down in the form of formal value statements, to influence organizational practices (Hofstede 1998). Barnard (1938) decades ago noted that one of the key functions of executives is to "formulate and define the purposes, objectives, and ends of the organization" and ensure a communication channel for these. 
Managers in many organizations have espoused a set of values to increase organizational performance and motion organizational culture in a desired direction. According to several studies, organizations well familiar with their value system and can utilize and mold it will succeed (e.g. Peters \& Waterman 1982, Beck \& Hillmar 1986, Deal \& Kennedy 1982). Espoused values do not always coincide directly with the values-in-use, i.e. the prevailing corporate culture (Schein 1985, Argyris \& Schön 1978). However, it has been proposed that they have a potential change impact on organizational culture by achieving a dynamic gap between current and ideal culture (Hatch 1993, Reger et al. 1994). Imitation of an "ideal" set of values such as that listed by Peters and Waterman (1982) is not related to successful financial performance (Barney 1986, Denison 1990). Therefore, values as well as ways of promoting them need to be tailored for each organization that wishes to use values for cultural change or maintenance.

One-directional communication of values does not ensure that the values are adopted and adhered to (Ledford et al. 1995). Rather, promotion of values should be looked at as a learning process where current beliefs are made accessible and, thus, changeable and new ones are brought into place (e.g. Hatch 1993, Dixon 1993). The criteria for successful values promotion range from a compelling set of statements and effective implementation process to consistent statements, systems and practices and continuous renewal (Ledford et al. 1995, Martinsuo 1996). What typically causes failures in these processes is management impatience in carrying out the process in full, lack of commitment or involvement, poor resources and low investment, and the poorly managed implementation phase (Blackler \& Brown 1980, Martinsuo 1996). In many successful cultural transformation efforts, the desired principles and values are not only promoted at the start but reinforced by supportive changes in organizational systems and procedures. Reger et al. (1994) refer to this as tectonic change where large leaps are supported by continuous improvements.

\subsection{Tailored games to promote organizational values}

Existing literature does not address the lack of concrete tools to promote organizational values in particular. Socialization and communication literature mentions the role of values, but does not provide actual tools (e.g. Van Maanen \& Schein 1979). In making beliefs accessible, dialogue (Schein 1985 , 1993, Dixon 1994), story telling (Boyce 1995), and systems thinking (Senge 1990) are considered important. The aspects of the simulation games mentioned above show promise in the context of promoting organizational values. 
In the field of ethics, culture and values simulation games have been used for instance to teach business ethics (Wolfe \& Fritzsche 1998) and to practice ethical decision-making in counselling (Frame et al.1997). Employee behaviour issues have largely been omitted from strategic management games (Keys 1997). As presented above, values are organization-specific. Thus, if simulation games are used in value promotion, it seems that tailored simulation games are needed. As well, general ethics games call for tailored vignettes to handle company-specific topic to make learning applicable within a real-life context (e.g. Wolfe \& Fritzsche 1998).

We propose that tailored, interactive and experiental simulation games can be used to promote organizational values, and below seek the factors that are relevant in creating such a game. This is approached through an application: a game designed to promote certain values in an industrial firm in Finland.

\section{APPLICATION: TRUMP CARD GAME}

A starting point for the game design process was an electronics industry firm's need to communicate values in a way suitable to its current culture and supportive of other ongoing development efforts. The value process was initially management-driven, but a decision was made to involve key personnel in delivering the value message to about 2000 people around the country in an interactive simulation game format. The aim of the game design project was to design a prototype for a game, test it, and train game facilitators. The company's role was to implement the game technically and bring it into use. The game can be considered both a teaching game and a policy game (Peters et al. 1998) in the sense that it was both to teach about the values of the firm and explore possible policy options in solving valuerelated problems.

The game design process followed the recommendations of Duke (1980), Greenblat and Duke (1981), Walter \& Marks (1981), Greenblat (1988), and Ruohomäki (1992), as shown in Figure 1. Firstly, an analysis was made of the current state in the firm. Secondly, the organizational reality was modelled and game assumptions were defined. Thirdly, the game was operationalized as a board game with cards and player teams. Fourthly, a prototype of the game was made and tested within the design team, with a corresponding team in the organization, and finally in a real-life context. After this, game facilitators were trained, and the final physical design of the game and its implementation were carried out in the company. 


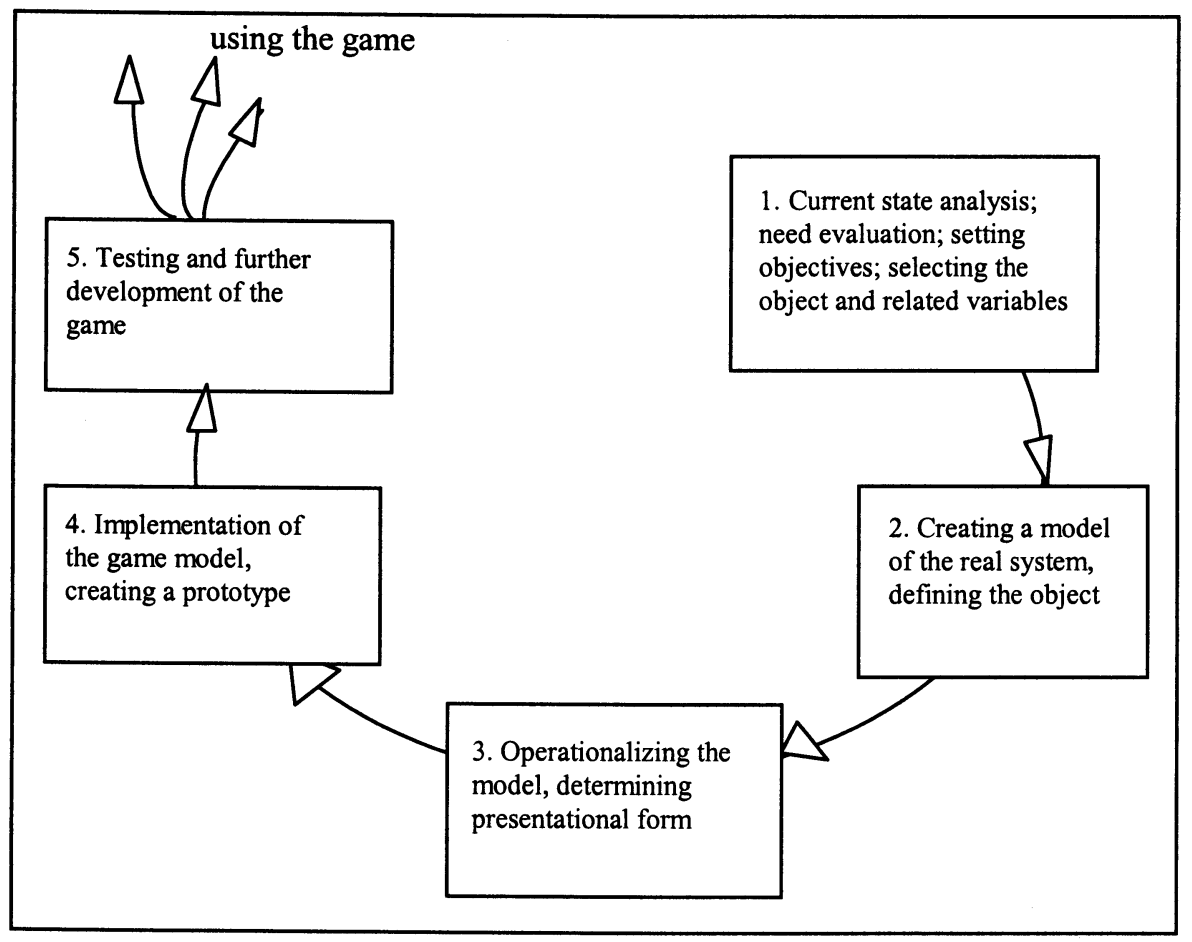

Figure 1. Developing a simulation game (Duke 1980, Greenblat \& Duke 1981, Greenblat 1988, Walter \& Marks 1981, Ruohomäki 1992).

A brief analysis of the current state of the organization was made to form a picture of the organizational context. Twenty-five key persons ranging from management to customer interface were interviewed, and material written about the firm, its values, and other development programs was examined. The objectives of the interviews were to get an idea of how well people knew the espoused values; how those values were interpreted; and to what extent were the espoused values in line with the values-in-use. Also, one aim was to gather information on how well people knew the so-called Trump Card roles, i.e. managerial roles defined in another company-wide project, and whether these could be linked to the game.

The main findings of the interviews were that values are agreed upon and practiced in part, but often performance issues are favoured if there's a conflict. A number of problematic situations and issues were discovered at this stage: for instance, modes of action do not always support espoused values, and some of the values are better known than others and have a more dominating role. Values were well in line with the managerial Trump Card roles, meaning that this could be used as support in the game. 
The objectives of the game focused on delivering the values to personnel and enhancing in a supportive manner value-based ways of operation. The game was to:

- communicate the organization's values to personnel and enable the creation of personal meaning for them

- promote a collective interpretation of the values through common experiences and discussion

- frame the difference between current and ideal, desirable ways of operating in the group, and thereby

- create a fertile ground for value-supportive actions

The game was operationalized as a board game with men, dice, and task and fact cards. The phases of the game are introduction, playing and reflection. The game is sufficiently general to suit everyone in the organization.

The player teams are to wander in the "world of values" visually presented on a map of five value "states" with "capitals". The goal is to visit all the capitals and in each of them collect a stamp for the team's passport. Teams proceed to these capitals through different types of tasks which handle real-life work situations, such as successes, decisions, problems, and changes. The tasks have to be accomplished through the interpretation of values, as is the case in a real-life context. Participants play as themselves, within their own work roles. The Trump Card roles are used occasionally as well. The first team to get five stamps wins the game.

Evaluation of the game design

Above, we described an application of a simulation game in promoting organizational values in an electronics industry company. The game design will now be evaluated on the basis of validity. Other important issues, such as those concerning usability and effectiveness, are left for a later analysis.

Raser (see Peters et al. 1998) presents four criteria for the validity of gaming as a research tool, namely psychological reality, structural validity, process validity, and predictive validity. These seem to apply to training and policy tools too. According to Peters and Associates (1998), the validity of the game can be improved by working systematically in a participative manner, checking the validity explicitly, and testing the game.

The first criterion is psychological reality, which has to do with providing a realistic environment. The Trump Card Game was created by a team of internal organizational members and external experts, where the role of the organization's internal members was especially to make sure that the game was realistic. Validity was checked with organizational members, and several tests were also made both with outsiders and insiders. However, the initial organizational analysis was rather light, so new information had to be 
collected later to finish the task cards. A more comprehensive analysis at the start would guarantee improved validity.

Structural and process validity refer to the congruency between the elements in the game system and the reference system. Validity can be evaluated by the structure (the theory and assumptions on which the game is built) or by the processes that take place in both systems. If the game is not related to the organization's or the person's job situation, there is the danger that playing the game will be considered a waste of time. Therefore, choosing the game becomes critical (Riis 1996). If the game is companyspecific, this risk will be smaller. Here, the company-specific nature and overall generality of the game likely promotes validity. Despite this, employees do have different jobs and the applicability of task card content to these jobs varies. In this sense, the validity of the game model could be further improved by designing different versions of the task cards for different contexts (e.g. sales tasks, technical tasks, support functions).

The last criterion, predictive validity, refers to reproducing historical outcomes or predicting the future. As for the Trump Card Game, handling values through real-life topics potentially ensures the transfer of learning to everyday work. It also enhances interactiveness and dialogue, promotes a collective experience, and thus, has a potential impact on collective beliefs and ways of working. During the creation of the game, managerial involvement and support existed at least to some extent, and the game was tied to other organizational development programs. Therefore, it is unlikely to remain a separate, temporary program but, rather, may become part of the organization's routine and supported by other efforts. However, design of the game cannot correct the mistakes made at the corporate management level, such as during the creation of the values.

\section{DISCUSSION}

Based on literature on value-promotion, and our empirical experience, we propose four characteristics as relevant in games that are used in promoting organizational values: a tailored content; explicitness of values; a chance to interpret, discuss, act on and question values; and, the visibility of a gap between current and ideal ways of working.

Tailored content. Despite the cost and effort of tailoring a simulation game for one organization's use, values and their promotion, in order to produce competitive advantage (e.g. Barney 1986) need to be companyspecific and tailored. In a company-specific game, players very quickly capture the idea, context and operation of the game due to the firm's familiarity, and the game can effectively stimulate organizational change 
processes (Riis 1996). At the same time, the game should be sufficiently general and adaptable so that it could suit the needs of different functions, personnel groups, and also different purposes within the firm. The topics in the Trump Card Game are in nature fairly general to suit the needs of various groups within the firm, but simultaneously they are strongly tied to the industry in question, the nature of service work, and certain events in the organizational history. In our experience, involvement of organizational members in designing the company-specific values promotion game is crucial in many ways, from verifying the commitment to the values and investment in the values promotion process, to demonstrating involvement at many levels and ensuring consistent implementation of values by other means. We currently assume that part of the game format could be general and adoptable in other firms, but the content needs tailoring and strong organizational involvement. The relationship between the generality of format and content tailoring is an interesting topic for future study.

Explicitness of values. Due to the original purpose of promoting values learning certain priorities and ways of working - the espoused values need to be made explicit in the game in some way. As Ledford and Associates (1995) stated, realization of organizational philosophy or values requires that the statements be compelling and communicated consistently. The players need to realize what the values are and why they are important. Additionally, if people are to use the values as guidance in their decision making, valuerelated situations must be made visible. In the Trump Card Game, the values were contained both as visible words ("states") in the "world of values" and as invisible, discussable ideals in the tasks related to daily interactions with customers and co-workers. Because of the nature of the values game, we see that various values, not only those espoused by company management, may come up during the game but that afterwards players should have a clear image of what is considered important in the firm in question.

A chance to interpret, discuss, act on and question values. The idea of promoting values implies that employees are not only recipients and listeners but also active interpreters and influential persons. Only if they have a chance to define values in their own terms, translate values into tangible actions, and negotiate meanings for the values, can they develop personal and collective commitment to the topic and select suitable behavioural responses (e.g. Louis 1980). In this sense, the experiential learning aspect of simulation games is particularly important. Also, interaction and cooperation are required to promote collective experience and, thus, shared understanding. In the Trump Card Game, choices and arguments have to be negotiated among the team members, and each team has to develop a collective response to various tasks. This not only forces individuals to think 
about their own priorities and opinions but also promotes dialogue and reflection within and between groups.

The visibility of a gap between current and ideal ways of working, and action orientation. If values are promoted with an aim to adapt ways of working to suit the values at either the individual or organizational level, the differences between ideals and reality must be made visible (e.g. Reger et al. 1994), and actions towards the values need to be supported. Action orientation within the game can come up in many ways. It may mean the presence of a committed key person who is able to respond to a value-related critique and needs of improvement, and ensure actions after the game. It may also mean a "development contract" among game players, to be implemented after the game, written development plans, and so on. In theTrump Card Game, most of the tasks are based on everyday types of work situations, ensuring that participants are familiar with them and values are discussed within a context. Working in groups reinforces sure that there is no "one correct solution" and that gaps between values and reality, or different ways of working become very easily visible. The presence of a trained game facilitator, encouraging games within natural work groups, and certain tasks have been used to promote action orientation and learning transfer.

In addition to particular game characteristics, other organizational systems and practices (e.g. HR) need to support the content promoted by the game, and the implementation of the game itself needs to be congruent with the values. The position of simulation games amongst different forms of values promotion is one potential topic for research in the future. Other research and development ideas have arisen due to an evident lack of empirical data in the field. Evaluation of the Trump Card Game usability and effectiveness is the initial research agenda in the case company. It would be of importance to study in parallel the impacts of a game and other communication and socialization mechanisms such as slide shows, more traditional forms of training, or written material. Different types of games can be used for the same purpose, and could be compared to test the validity of the above-mentioned critical factors in values games. Another question is whether a common value game should be developed or does it always have to be tailored.

\section{REFERENCES}

Argyris, C. \& Schön, D. A. (1978) Organizational Learning: A Theory of Action Perspective. USA: Addison-Wesley Publishing Company.

Barnard, C. (1938) The Functions of the Executive. USA: Harvard University Press. 
Barney, J. B. (1986) Organizational Culture: Can It Be a Source of Sustained Competitive Advantage? Academy of Management Review 11 (3) 656 - 665.

Beazley, H. and Lobuts, J. Jr. (1996) EXECUTIVE DECISION - exploring the psychological contract. In D. Saunders, F. Percival and M. Vartiainen (Eds.) The Simulation and Gaming Yearbook Volume 4: Games and Simulations to Enhance Quality Learning, 141 - 155. Guildford and King's Lynn, Great Britain: Kogan Page Ltd.

Beck, A. C. \& Hillmar, E. D. (1986) Positive Management Practices. Bringing out the Best in Organizations and People. USA: Jossey-Bass Publishers.

Blackler, F. H. M. \& Brown, C. A. (1980) Whatever Happened to Shell's New Philosophy of Management? Lessons for the 1980s from a Major Socio-Technical Intervention of the 1960s. Southampton, Great Britain: Teakfield Limited.

Boyce, M. E. (1995) Collective centring and collective sense-making in the stories and storytelling of one organization. Organization Studies 16 (1) $107-137$.

Deal, T. E. \& Kennedy, A. A. (1982) Corporate Cultures. The Rites and Rituals of Corporate Life. USA: Addison-Wesley Publishing Company, Inc.

Denison, D. R. (1990) Corporate Culture and Organizational Effectiveness. USA: John Wiley \& Sons.

Dixon, N. (1994) The Organizational Learning Cycle. How We Can Learn Collectively. Great Britain: McGraw-Hill Book Company.

Duke, R.D. (1980) A paradigm for game design. Simulation and Games 11, 364-377.

Forssén-Nyberg, M. \& Kutilainen, P. (1998) Participative simulation game as facilitator of organizational development process - two case studies. In: Smeds, R. \& Riis, J. O. (Eds.) Experimental Learning in Production Management, The effects of using simulation games in universities and industry, 39-49. London: Chapman \& Hall.

Frame, M. W., Flanagan, C.D., Frederick, J., Gold, R., Harris, S. (1997) You're in the Hot Seat: An Ethical Decision-Making Simulation for Counseling Students. Simulation \& Gaming 28 (1) 107-115.

Goldstein, D. L. (1996) Culture Clash: An Ethical Intercultural Simulation (Groff, L. and Smoker, P. 1995). Simulation \& Gaming 27 (3) 416 - 418.

Greenblat, C. S. (1988) Designing games and simulations. London: Sage Publications.

Greenblat, C. S. \& Duke, R. D. (1981) Principles and practices of gaming-simulation. London: Sage Publications.

Haho, P. (1998) Tailored simulation games for successful business process development. In: Smeds, R. \& Riis, J. O. (Eds.) Experimental Learning in Production Management, The effects of using simulation games in universities and industry, 24-38. London: Chapman \& Hall.

Hatch, M. J. (1993) The Dynamics of Organizational Culture. Academy of Management Review 18 (4) 657 - 693.

Hofstede, G. (1998) Attitudes, Values and Organizational Culture: Disentangling the Concepts. Organization Studies 19 (3) 477 - 492.

Keys, J. B. (1997) Strategic Management Games: A Review. Simulation \& Gaming 28 (4) $395-422$.

Kluckhohn, F. \& Strodtbeck, F. (1961) Variations in Value Orientations. Evanston, IL: Row, Peterson.

Ledford, G. E. Jr., Wendenhof, J. R. and Strahley, J. T. (1995) Realizing a Corporate Philosophy. Organizational Dynamics 23 (3) 5 - 19.

Louis, M. R. (1980) Surprise and Sense Making: What Newcomers Experience in Entering Unfamiliar Organizational Settings. Administrative Science Quarterly 25 (2) 226 - 251. 
Martinsuo, M. (1996) Espoused values in managing organizational culture. An unpublished Licentiate Thesis, Helsinki University of Technology, Department of Industrial Management, Espoo, Finland.

Peters, T. J. \& Waterman R. H. (1982) In Search of Excellence. USA: Warner Books Inc.

Peters, V., Vissers, G. and Heijne, G. (1998) The Validity of Games. Simulation \&Gaming 29 (1) $20-30$.

Piispanen, E. (1995) The simulation game starts the change process. Case example from a Provincial Government of Turku and Pori. Report of the Productive Office (Proffice) project. The Finnish National Productivity Programme. Espoo: Otapaino. (in Finnish)

Piispanen, E., Ruohomäki, V., Pankakoski, M. \& Teikari, V. (1996). The Work Flow Game A new method for developing office work. In Saunders, D., Percival, F. \& Vartiainen, M. (Eds.). The Simulation and Gaming Yearbook, Volume 4: Games and Simulations to Enhance Quality Learning. London: Kogan Page.

Reger, R. K., Mullane, J. V., Gustafson, L. T. and DeMarie, S. M. (1994) Creating Earthquakes to Change Organizational Mindsets. Academy of Management Executive 8 (4) $31-45$.

Riis, J.O. (1996) Games for implementing changes in industrial enterprises. In D. Saunders, F. Percival and M. Vartiainen (Eds.) The Simulation and Gaming Yearbook Volume 4: Games and Simulations to Enhance Quality Learning, 72 - 84. Guildford and King's Lynn, Great Britain: Kogan Page Ltd.

Rokeach, M. (1968) Beliefs, Attitudes, and Values. York, Pennsylvania: Jossey-Bass, Inc.

Ruohomäki, V. (1992) Simulation games - an overview of concepts and applications possibilities. In: Simulation games as educational tools in the learning organisation. Helsinki University of Technology, Industrial Management and Industrial Psychology, Report 140, HUT, Espoo, 1-27 (in Finnish).

Ruohomäki, V. (1994). Simulation games and their effects - the Work Flow Game for the development of administrative work. Licentiate's Thesis, Helsinki University of Technology, Industrial Economics and Industrial Psychology, Report No 156, HUT, Espoo. (in Finnish)

Ruohomäki, V. (1995). A simulation game for the development of administrative work processes. In Saunders, D. (Ed.) The Simulation \& Gaming Yearbook 1995, Vol 3. London: Kogan Page, p. 264-270.

Schein, E. H. (1985) Organizational Culture and Leadership. USA: Jossey-Bass Inc., Publishers.

Schein, E. H. (1993) On Dialogue, Culture, and Organizational Learning. Organizational Dynamics 22 (2) 40 - 51.

Senge, P. (1990) The Fifth Discipline. The Art \& Practice of the Learning Organization. Great Britain: Century Business.

Smeds, R. (1996). Management of Enterprise Evolution. Evolution Management Principles and Methods for Learning Organizations. Doctoral Dissertation. Acta Polytechnica Scandinavica, Mathematics, Computing and Management in Engineering Series No. 80, The Finnish Academy of Technology, Helsinki.

Van Maanen, J. and Schein, E. H. (1979) Toward a Theory of Organizational Socialization. In B. M. Staw (Ed.) Research in Organizational Behavior, Vol. 1., 209 - 264. Greenwich, CT, USA: JAI Press, Inc.

Walter, G.A. \& Marks, S.E. (1981) Experiential learning and change: Theory, design and practice. New York: Wiley.

Wolfe, J. \& Fritzsche, D.J. (1998) Teaching Business Ethics With Management and Marketing Games. Simulation \& Gaming 29 (1) 44-59 


\section{BIOGRAPHY}

\section{Heini Ikävalko}

Heini Ikävalko is a researcher at Helsinki University of Technology, Department of Industrial Engineering and Management. Working at the Laboratory of Work Psychology and Leadership, she has been involved in projects for organisation development, especially with developing and disseminating new methods. Professional interests include knowledge management, organisational learning, participative process development, simulation/gaming,

Miss Ikävalko holds a Master of Education, majoring in adult education.

\section{Miia Martinsuo}

Miia Martinsuo, Dr. Tech., previously worked as Project Manager at Helsinki University of Technology, Department of Industrial Engineering and Management in the field of Organisation Development. Her topics of interest include general organisation management, organisational culture and values, organisational innovation and simulation games. She has conducted research and development projects mainly with multinational industry organisations and involved in European research collaboration in organisation development and continuous innovation. She has recently completed her doctoral dissertation on the promotion of values in a multinational enterprise and currently works as product manager at Nokia Group. 